\title{
Intention to Donate Blood Among Health Care Workers of Hadiya Zone, Southern Ethiopia
}

\author{
Kifle Lire Ratebo*, Amene Abebe Kerbo, Befekadu Bekele Beshah \\ School of Public Health, College of Health Science and Medicine, Wolaita Sodo University, Sodo, Ethiopia \\ Email address: \\ kiflelire@gmail.com (K. L. Ratebo), ameneabebe@yahoo (A. A. Kerbo), befekadubekele1979@gmail.com (B. B. Beshah) \\ ${ }^{*}$ Corresponding author
}

\section{To cite this article:}

Kifle Lire Ratebo, Amene Abebe Kerbo, Befekadu Bekele Beshah. Intention to Donate Blood Among Health Care Workers of Hadiya Zone, Southern Ethiopia. American Journal of Life Sciences. Vol. 8, No. 4, 2020, pp. 76-81. doi: 10.11648/j.ajls.20200804.15

Received: May 27, 2020; Accepted: June 28, 2020; Published: August 25, 2020

\begin{abstract}
Background: Many people in the developing world die unnecessarily because of a shortage of blood for those in need. Securing sufficient blood in health care facilities is among the crucial components of effective health care services delivery. Health care workers are very close to patients in need of blood transfusion than anyone else. However, the donation of blood mostly depends voluntarily. Therefore, this study aimed to assess the level of intention to donate blood and associated factors among health care workers of Hadiya Zone, Southern Ethiopia. Methods: Facility-based crosssectional study design was conducted applying the Theory of Planned Behavior from November to December 2018. A total of 394 participants recruited the study with a response rate was $97 \%$. Health centers were selected randomly and then the total sample size was proportionally allocated based on the number of health workers in each health center. A simple random sampling method was applied to select study participants. A structured questionnaire was used to collect data. Pearson Correlation coefficient was used to determine the correlation of intention with the theory of planned behavior constructs. Descriptive statistics were used to describe sample characteristics. Multiple linear regression analysis was done to identify predictors of intention to blood donation. Standardized $\beta$ coefficients and adjusted $R^{2}$ values were used to interpret the effects and variability in the dependent variable, respectively. A $P$-value of $\mathrm{P}<0.05$ was used to declare the presence of a statistical association. Result: The theory of planned behavior explained $34.8 \%$ of the total variability of intention to donate blood. The Mean of participants Intention to donate is 10.73 (+SD 3.04). Attitude to donate blood $[\beta=.303 ; \mathrm{P}<0.0001]$; Subjective norm $[\beta=.320 ; \mathrm{P}<0.0001]$; Perceived behavioral control $[\beta=.101 ; \mathrm{P}<0.001]$. Sociodemographic variables, knowledge about donation and donation experience did not predict the intention to donate blood. Conclusion and Recommendations: Attitude to donate blood, Subjective norm towards blood donation, and perceived behavioral control to donate blood were significant predictors of behavioral intention to donate blood explaining $34.8 \%$ of total variability in the behavioral intention to donate blood. Interventions aimed at addressing attitude, subjective norms and perceived behavioral control need are recommended.
\end{abstract}

Keywords: Intention, Blood Donation, Theory of Planned Behavior, Health Care Workers

\section{Introduction}

Many people in the developing world die in hospitals as a result of blood shortage. An increase in road traffic accidents, complications during pregnancy, childbirth, severe childhood anemia, trauma and the management of congenital blood disorders and Hemorrhage has led to chronic blood shortages in developing countries $[1,2]$.

According to the World Health Organization (WHO) statistic, developing countries are collecting only $45 \%$ of blood and blood products of the need of the countries. In Ethiopia the proportion of blood collected from voluntary blood donors has increased from $10 \%$ in 2012 to $98 \%$ in 2014, However, currently, only about 200000 units of blood are collected per year, but the need of blood for the country to fulfill the need of patients is about 900000 . Which is only about 19\% [2-4].

Ensuring sufficient supplies of safe blood is among the crucial components of health care services. It contributes to saving millions of lives in routine and emergencies, allows 
increasingly complex medical and surgical interventions and dramatically improves the life expectancy and quality of life of patients with a variety of acute and chronic conditions. Health care workers are key partners who can motivate the community to become voluntary donors and very close to patients in need than anybody else [5].

World Health Organization (WHO) recommends countries to focus on young people to achieve $100 \%$ no remunerated voluntary blood donation by 2020 . It also recommends that all countries should be self-sufficient in all blood products and that all blood donations should be voluntary, anonymous, and no remunerated $[5,6]$.

Studies have shown that being informed about blood transfusion, educational status, knowledge, attitude, selfefficacy, subjective norms were predictors of intention to donate blood [7, 8]. Study conducted among health care workers of black lion hospital shows that only (54.2\%) of respondents have good level of knowledge regarding blood donation. Health workers aged between $31 \& 40$ were 1.5 times having good attitude towards blood donation than those who are above 40 [9].

Although large proportion of health workers in Ethiopia are eligible to donate blood most of them did not engage voluntarily in blood donation. This implies there is a need to develop better strategies to access this enormous donor pool. In order to develop an effective strategy, it is critical to have a clear understanding of factors that influence people not to donate blood. A number of psychological theories have been developed in an attempt to identify the range of issues influencing the donation intention $[7,8,11]$.

The Theory of planned behavior (TPB) was applied for this research since it operates on the premise that the best way to predict behavior is to measure behavioral intention, which in turn is seen to be a function of three independent variables, i.e. attitude, subjective norm and perceived behavioral control. Attitude is an individual's positive or negative evaluation of behavior, is seen to reflect beliefs about the likely consequences of performing a behavior, whilst subjective norm is an individual's perception of social pressure and thus reflects the beliefs about the normative expectations of others. Perceived behavioral control, is a reflection of the perceived ease or difficulty involved in performing a behavior [12].

Little is known about the intention to donate blood in the study area. Therefore, this study aimed to assess the level of intention to donate blood and associated factors among health care workers of Hadiya Zone, Southern Ethiopia.

\section{Methods and Materials}

\subsection{Study Design and Setting}

A facility-based cross-sectional study design was conducted to assess the level of intention to donate blood and associated factors among health care workers in Hadiya zone southern Ethiopia which is located $232 \mathrm{~km}$ away from the capital city of Ethiopia Addis Ababa from November to
December 2018. There were three hospitals and 61 health centers. All health workers working in Hadiya zone health facilities were source population and those health workers in the selected health centers and hospitals available during the study period were the study population.

\subsection{Sample Size and Sampling}

The sample size was determined by using single population proportion formula by taking the prevalence of intention to blood donation from northern Ethiopia [8]. $(P)=37 \% \quad Z=$ Standard normal distribution value at $95 \%$ confidence level of $Z \alpha / 2=1.96,5 \%$ of absolute precision, and $10 \%$ non-response rate. Thus the total sample size was 394. The total sample size was proportionally allocated to the total health care workers in each health facility in the Zone and the required sample size from each health facility was selected by simple random sampling using a sampling frame of health workers in each health facility.

\subsection{Measurements}

Intention to donate blood was measured using three items. Responses ranged from "not likely at all" (1) to "very likely" (5). Responses to the three items were summed to get a measure of intention to donate blood.

Attitude toward blood donation was measured using three items. With respondents asked to indicate their level of agreement on a scale from "Strongly disagree" to "Strongly Agree." Subjective norm to blood donation norms were measured using five items, with respondents asked to indicate their level of agreement on a scale from "Strongly disagree" to "Strongly Agree." high composite score of subjective norms indicate positive social pressure (pressure in favor of the behavior) low composite score of subjective norm shows negative social pressure.

Perceived behavioral control was measured using four items With respondents asked to indicate their level of agreement on a scale from "Strongly disagree" to "Strongly Agree." High composite score indicates that donating blood is easy or under their control. The mean scores were used in the regression analysis for all components of the theory.

The past blood donation component considered whether an individual's past donation experience of HCWs at least once in their lifetime. One item is used to ask respondents whether they had been donating in the past by indicating "Yes" or "No" as appropriate.

\subsection{Data Collection Procedure}

Data were collected by using a structured questionnaire adapted and modified from previous studies. The questionnaire contains socio-demographic variables and TPB constructs. Directors of all selected health facilities were trained for half a day on the questionnaire and the purpose of the study and used as data collectors. Two supervisors from the Zonal health department with educational level Bsc were used. All selected health workers from the facilities were requested to fill the questionnaire on a self-administered 
basis.

\subsection{Data Management and Analysis}

Data were entered in Epi-info version3.5.4 checked for completeness, edited, coded, and carefully entered by the principal investigator and exported to SPSS version 20.1 for analysis. A descriptive statistical measure such as the means and standard deviations were undertaken. A multivariable linear regression analysis was performed to predict the intention to donate blood. Standardized $\beta$ coefficients and adjusted $R^{2}$ values were used to interpret the effects and variability in the dependent variable, respectively. A $P$-value, $5 \%$ was used to indicate an association.

\subsection{Ethical Considerations}

Ethical approval was obtained from the Ethical Review Committee of the School of Public Health, Wolaita Sodo University. A letter of permission was obtained from Hadiya Zone Health department to the respective health facilities that were included in the study. All the study participants were informed about the purpose of the study and finally, their oral consent was obtained before giving them a self-administered questionnaire. The respondents were assured their right to refuse or terminate at any point in the study.

\section{Results}

\subsection{Socio-demographic Characteristics}

A total of 382 respondents were included in the study making the response rate of $97 \%$. From the total respondents, $197(51.6 \%)$ were male and the rest were females. The mean age of the respondents was $27.56( \pm \mathrm{SD}=5.87)$ The Majority of the respondents $294(77 \%)$ were protestant religious followers and 261 (68.3) were Hadiya ethnic group. Among the respondents, slightly more than half of the 206 (53.9) were married. Concerning the profession of the respondents, majority 219 (57.3\%) of them were nurses diploma and BSC following lab technologists and technicians, midwives and health officers are nearly equal 37 (9.4\%), $36(9.2 \%)$ and 32 (8.4\%) respectively. As to the qualification of the participants, most of them 256 (67\%) were diploma and 126
(33\%) were BSC and above (Table 1).

Table 1. Socio-Demographic Characteristics of the study participants, Hadiya zone, southern Ethiopia $(n=382)$.

\begin{tabular}{|c|c|c|}
\hline Variables & Frequency & Percent \\
\hline \multicolumn{3}{|c|}{ Sex of the respondent } \\
\hline Male & 197 & 51.6 \\
\hline Female & 185 & 48.4 \\
\hline \multicolumn{3}{|l|}{ Religion } \\
\hline protestant & 294 & 77 \\
\hline orthodox & 53 & 13.9 \\
\hline Muslim & 30 & 7.9 \\
\hline other & 5 & 1.3 \\
\hline \multicolumn{3}{|l|}{ Ethnicity } \\
\hline Hadiya & 261 & 68.3 \\
\hline kembata & 26 & 6.8 \\
\hline gurage & 15 & 3.9 \\
\hline silte & 18 & 4.7 \\
\hline others & 62 & 16.2 \\
\hline \multicolumn{3}{|l|}{ Marital status } \\
\hline Married & 205 & 53.7 \\
\hline unmarried & 175 & 45.8 \\
\hline divorced & 2 & 0.5 \\
\hline \multicolumn{3}{|c|}{ The educational level of respondents } \\
\hline Diploma & 256 & 67 \\
\hline BSc and above & 126 & 33 \\
\hline \multicolumn{3}{|c|}{ Profession of respondents } \\
\hline Nurse & 219 & 57.3 \\
\hline Midwives & 35 & 9.2 \\
\hline Environmental & 27 & 7.1 \\
\hline Health officer & 32 & 8.4 \\
\hline Medical doctors & 16 & 4.2 \\
\hline Pharmacy & 17 & 4.5 \\
\hline Lab officers & 36 & 9.4 \\
\hline
\end{tabular}

\subsection{Past Blood Donation Experience}

Among the respondents less than half, 140 (36.6\%) of them have donated blood at least once before this survey, most of the respondents $242(63.4 \%)$ have never donated blood before. The reason for the respondent's blood donation $112(80 \%)$ was voluntary, $28(20 \%)$ for family replacement. The reason for the respondents who have never donated their blood was 65 (27.8\%) fear of fainting (Table 2).

Table 2. Donation experience related characteristics of study participants Hadiya zone, southern Ethiopia ( $n=382)$.

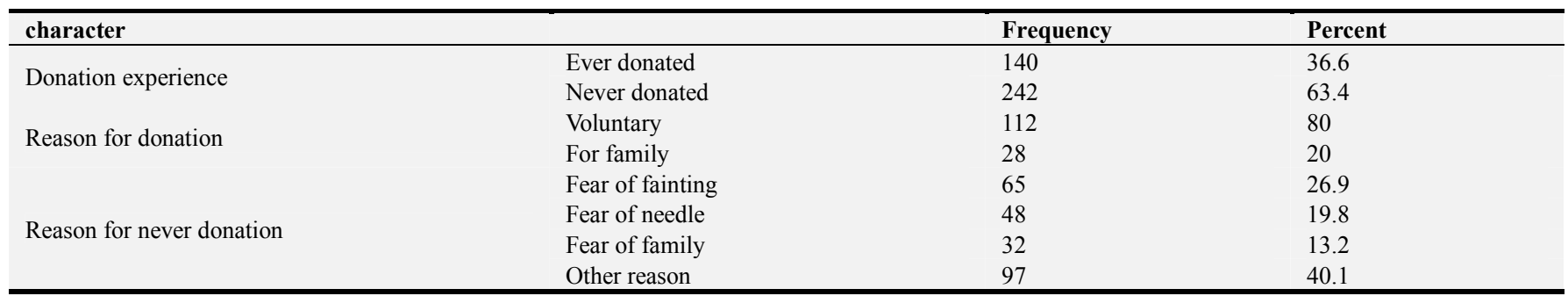

\subsection{Knowledge of Respondents About Blood Donation}

More than three fourth 299 (78.3\%) of the study population knows blood group, 294 (77\%) frequency of blood donation age of range of donation (Table 3 ). 
Table 3. Knowledge of study participants about blood donation Hadiya zone, southern Ethiopia ( $n=382)$.

\begin{tabular}{|c|c|c|c|}
\hline Knowledge & & Frequency & Percent \\
\hline \multirow{2}{*}{ Knowledge of bloodgroup of respondent } & Yes & 299 & 78.3 \\
\hline & No & 83 & 21.7 \\
\hline \multirow{2}{*}{ Knowledge about the age range for donation } & Yes & 294 & 77 \\
\hline & No & 88 & 23 \\
\hline \multirow{2}{*}{ Knowledge of weight for blood donation } & Yes & 269 & 70.4 \\
\hline & No & 113 & 29.6 \\
\hline \multirow{2}{*}{ Knowledge of frequency for blood donation } & Yes & 288 & 75.4 \\
\hline & No & 94 & 24.6 \\
\hline
\end{tabular}

\subsection{Correlation Analysis of Intention to Blood Donation}

As can be seen in the table below all constructs of the theory of planned behavioral models are significantly related with intention to blood donation, subjective norm, attitude, and perceived behavioral control have a significant positive association with intention to blood donation. With $(\mathrm{r}=0.526$ $\mathrm{N}=382 \mathrm{P}<0.00), \quad(\mathrm{r}=0.501 \mathrm{~N}=382, \mathrm{P}<0.00)$ and $(\mathrm{r}=.0 .276$ $\mathrm{N}=382, \quad \mathrm{P}<0.00)$ respectively of Pearson correlation coefficient.

Table 4. Correlation analysis between intention, subjective norm, attitude and perceived behavioral control, Hadiya zone, $n=382$.

\begin{tabular}{|c|c|c|c|c|c|}
\hline & & Intention & Attitude & Subjective norm & Perceived behavioral control \\
\hline \multirow{3}{*}{ Intention } & Pearson correlation & 1 & & & \\
\hline & Sig.(2-tailed) & & & & \\
\hline & $\mathrm{N}$ & 382 & & & \\
\hline \multirow{3}{*}{ Subjective Norm } & Pearson correlation & $0.526^{* *}$ & & & \\
\hline & Sig.(2-tailed) & 0.000 & & & \\
\hline & $\mathrm{N}$ & 382 & 382 & & \\
\hline \multirow[t]{2}{*}{ Attitude } & Sig.(2-tailed) & 0.000 & 0.000 & 0.000 & \\
\hline & $\mathrm{N}$ & 382 & 382 & 382 & \\
\hline \multirow{3}{*}{$\begin{array}{l}\text { Perceived } \\
\text { behavioral control }\end{array}$} & Pearson correlation & $0.276^{* *}$ & $0.187 * *$ & $0.37 * *$ & 1 \\
\hline & Sig. (2-tailed) & 0.000 & 0.000 & 0.000 & \\
\hline & $\mathrm{N}$ & 382 & 382 & 382 & 382 \\
\hline
\end{tabular}

Correlation is significant at the 0.01 level (2-tailed)**

\subsection{Descriptive Statistics of theTheory of Planned Constructs}

As it can be seen below the mean intention to donate blood 10.7 (SD +3.04), Attitude 11.65 (SD +2.36), Subjective norm $19.18(\mathrm{SD}+4.15)$ and Cronbach's alpha of each constructs $(0.91,0.74,0.86,0.62)$ respectively (Table 5).

Table 5. The results of the Cronbach's alpha analysis are presented with the mean scores and standard deviations for each scale, Hadiya zone, southern Ethiopia $(n=382)$.

\begin{tabular}{llll}
\hline Scale & No of items & Mean (SD) & $\boldsymbol{\alpha}$ \\
\hline Intention to donate blood & 3 & $10.7(3.04)$ & 0.91 \\
Attitude to donate blood & 3 & $11.65(2.36)$ & 0.74 \\
Subjective norm to donate blood & 5 & $19.18(4.15)$ & 0.86 \\
Perceived control to donate blood & 4 & $13.65(3.35)$ & 0.62 \\
\hline
\end{tabular}

\subsection{Predictors of Intention to Donate Blood}

Multiple linear regression analysis was done to identify predictors of intention to donate blood. Attitude $(\beta=.303 ; \mathrm{P}<0.0001)$; Subjective norm $(\beta=.320 ; \mathrm{P}<0.0001)$; Perceived behavioral control $(\beta=.101 ; \mathrm{P}<0.0001)$ (Table 6).

Table 6. Predictors of intention to donate blood among health workers, Hadiya zone, southern Ethiopia $(n=382)$.

\begin{tabular}{llll}
\hline Variables & Standardized $\boldsymbol{\beta}$ & P-value & 95\%CI for b \\
\hline Attitude & .303 & 0.000 & $(0.263,0.517)$ \\
Subjective norm & .320 & 0.000 & $(0.158,0.311)$ \\
Perceived behavioral control & .101 & 0.024 & $(0.012,0.172)$ \\
\hline
\end{tabular}




\section{Discussion}

This study explains the intention to donate blood among health workers in the Hadiya zone. Attitude to donate blood, subjective norm and perceived behavioral control to donate blood were predictors of intention to donate blood among health workers.

The finding of this study showed that Intention to donate blood is correlated with the theory of planned constructs Attitude, subjective norm and perceived behavioral control to donate blood. This is consistent with previous studies conducted that there was a significant association between intention to donate blood and constructs theory of planned behavior which is also in agreement with the founder of the theory [6-8].

Attitude to donate blood independently explained $25 \%$ variability of intention to donate blood and subjective norm explained $27.7 \%$ variability in intention to donate blood whereas perceived behavioral control explained $7.6 \%$ variability in intention to donate blood.

$36.6 \%$ of the study participants had donated blood at least once. Which was far different from the study conducted at the general population of Mekele city. Most of the respondents $111(79.9 \%)$ had donated voluntarily and about $28(7.3 \%)$ had donated for family which is lower than the study conducted in Saudi Arabia Thai bah University and Addis Ababa secondary schools. This could be due to the difference in the study setting and target groups since the intention to donate blood can vary across different settings and target groups as the proponents of the theory of planned behavior suggest [6].

Past blood donation experience is not positively associated with intention to donate blood which is far different from other studies [6, 7, 9-11]. But this finding is similar to the study done in the Tigray region Mekele town general population that showed those who had a history of blood donation had no intention of blood donation [8].

Attitude to donate blood, Subjective norm towards blood donation, and perceived behavioral control to donate blood were significant predictors of behavioral intention to donate blood explaining $34.8 \%$ of total variability in the behavioral intention to donate blood. Attitude $[\beta=.303$; $P<0.0001]$; For a unit positive change in the attitude of health care workers towards blood donation changed intention to donate blood by $30.3 \%$. Subjective norm $[\beta=.320 ; \mathrm{P}<0.0001]$; Which indicates the intention of blood donation depends on the perception of health workers on the social pressure. For a unit positive change in perception of health workers on the social pressure intention to donate changed by $32 \%$. Perceived behavioral control $[\beta=.101 ; \mathrm{P}<0.001]$. This indicates that the intention of health workers to donate blood depends on attitude about donation, subjective norms and perceived behavioral control. This is consistent with the study conducted at Virginia among military intention to blood donation $[12,13]$. However, none of the socio-demographic factors predicted the behavioral intention to donate blood which is inconsistent with the previous study conducted in the northern part of Ethiopia where the education status of respondents is a predictor of behavioral intention to donate blood.

\section{Conclusion and Recommendations}

The findings indicated that the theory of planned behavior is applicable for predicting intention to donate blood. Attitude to donate blood, subjective norm and perceived behavioral control to donate blood were independent predictors of intention to donate blood in the context of health care workers. Attitude to donate blood was found to be most important factor associated with behavioral intention followed by subjective norm to donate blood. Behavior change interventions should focus to address attitude, subjective norms and perceived behavioral control to donate blood. Further study should be done on factors affecting the behavioral intention in addition to the constructs of the theory of planned behavior.

\section{Competing Interests}

The authors declare that they have no competing interests.

\section{Availability of Data and Materials}

Datasets will not be shared to protect the participants' confidentiality

\section{Authors' Contributions}

$\mathrm{KL}, \mathrm{AA}$, and $\mathrm{BB}$ designed the study, analyzed the data, drafted the manuscript and critically reviewed the article. All authors read and approved the final manuscript.

\section{Funding}

This research received support from Wolaita Sodo University

\section{Acknowledgements}

We would like to thank Wolaita Sodo University, school of public health for its co-operation in doing the research. Our heartfelt thanks also go to all of the participants of this study.

\section{References}

[1] Amatya DM. Study on Knowledge, Attitude, and Practice of Blood Donation among Students of Different Colleges of Kathmandu, Nepal. International Journal of Pharmaceutical \& Biological Archives. 2013.

[2] WHO. Blood donation safety report, 2006; 92: 14-7.

[3] J. B. Tapko PMaAJD-N. status of blood safety in the African region. 2006.

[4] World Health Organization. blood supply and availability in June 2011. 
[5] WHO. World Blood Donor Day: New Blood for the World, WHO, Geneva, Switzerland, 2010.

[6] Njuguna N. Factors influencing blood donation at selected sites in Nairobi, Kenya Njambi Njuguna.

[7] Nur Zainie Abd Hamid RB, and Narehan Hassan. Factors Influencing the Intention to Donate Blood: International Journal of Social Science and Humanity, July 2013; Vol. 3.

[8] Gebremeskel Mirutse GF, Lakew Abebe, Zewda Birhanu, Mussie Alemayehu. Intention to Donate Blood among the Eligible Population in Mekelle City, Northern Ethiopia: American Journal of Health Research. 2014; Vol. 2, No. 4.

[9] Nojood H. Al-Rahili. Knowledge and Intentions toward Blood Donation among Medical Students of Taibah University, Madinah, Saudi Arabia 2015; vol 4.
[10] Godin G, Sheeran P, Conner M, Germain M, Blondeau D, Gagné C, et al. Factors explaining the intention to give blood among the general population. Vox Sanguinis. 2005; 89 (3): $140-9$.

[11] Ben Natan Merav RN PLA, Gorkov Lena RN, BA (Nurse) b, 1. Investigating the factors affecting blood donation.

[12] Jillian J, Martin P Eccles, Marie J, Anne W, Jeremy G, Robbie F, Eileen FS Kaner, Liz Smith, Debbie B: constructing questionnaires based on the theory of planned behavior; a manual for health services researchers. May 2004.

[13] Shambel Wedajo Ss, Mengesha Beley, Prof (Dr.) P. Surender Reddy. Blood.

[14] K. W. The guideline for appropriate clinical use of blood. 2006 May. 